\title{
Generic framework for conceptual design using concurrent engineering strategy. A case study: advanced material application - product development of metal matrix composite component
}

\begin{abstract}
One of the keys to success for product competition in the market depends on the effectiveness of its product development. This article presents a generic framework of product development which focuses on the conceptual design. The framework is developed with concurrent engineering strategy where it takes into account the product life cycle considerations within the early phases of the conceptual design. The proposed framework starts from product investigation, product specification and conceptual design. Implementation of the framework is illustrated on a case study of metal matrix composite brake disc rotor design, where there is an avenue for conceptual research since the progress of metal matrix composite utilisation in the automotive industry is limited due to their high cost in comparison with conventional alloy. The possible outcome for product investigation, product specification and conceptual design of metal matrix composite brake disc rotor are presented as part of the selection of best conceptual design. Moreover, the proposed framework is an aid to help engineers and designers to make an effective and systematic product development through a sound conceptual design decision from possible product concept alternatives.
\end{abstract}

Keyword: Brake disc rotor; Conceptual design; Concurrent engineering; Metal matrix composite (MMC); Product development; Product investigation; Product specification 